\title{
Prevalence of gestational diabetes and associated maternal and neonatal complications in a fast-developing community: global comparisons
}

This article was published in the following Dove Press journal:

International Journal of Women's Health

4 November 2011

Number of times this article has been viewed

\author{
Abdulbari Bener ${ }^{1,2}$ \\ Najah M Saleh ${ }^{3}$ \\ Abdulla Al-Hamaq ${ }^{4}$ \\ 'Department of Medical Statistics \\ and Epidemiology, Hamad Medical \\ Corporation, Hamad General \\ Hospital, Department of Public \\ Health and Medical Education, \\ Weill Cornell Medical College, \\ Qatar; ${ }^{2}$ Department of Evidence for \\ Population Health Unit, School of \\ Epidemiology and Health Sciences, \\ University of Manchester, Manchester, \\ UK; ${ }^{3}$ Department of Obstetrics \\ and Gynecology, Women's Hospital, \\ Hamad Medical Corporation, Qatar; \\ ${ }^{4}$ Qatar Diabetes Association and \\ Qatar Foundation, Qatar
}

Background: The prevalence of gestational diabetes (GDM) is increasing all over the world. Hence, the impact of GDM on maternal and infant health is an important topic of research. No study has been conducted in Qatar to evaluate the outcome of pregnancies complicated by diabetes mellitus.

Objective: The aim of the study was to determine the prevalence of GDM, compare the maternal-neonatal complications among women with GDM and non-GDM pregnant women, and investigate the risk factors and potential outcomes associated with GDM.

Design: This is a prospective cohort study.

Setting: The survey was carried out at the antenatal clinics of the Women's Hospital, Qatar.

Subjects and methods: A representative sample of 2056 pregnant women who attended the antenatal clinics of the Women's Hospital were surveyed during the period from the first week of January 2010 to April 2011. From this sample, 1608 women (78.2\%) expressed their consent to participate in the study. Questionnaires were administered to pregnant women who were seeking antenatal care at this urban hospital. The questionnaire covered variables related to sociodemographic factors, family history, medical history, maternal complications, and neonatal outcome.

Results: The prevalence of GDM in Qatar was 16.3\%. Women with GDM were significantly higher in the age group of $35-45$ years $(45 \% ; P=0.001)$. Family history of diabetes $(31.7 \%$; $P<0.001)$, increased parity $(55.3 \% ; P=0.004)$, and obesity $(59.2 \% ; P<0.001)$ were determinants of GDM in pregnant women. Maternal complications like pregnancy-induced hypertension $(19.1 \%$ vs $10.3 \% ; P<0.001)$, pre-eclampsia $(7.3 \%$ vs $3.8 \% ; P=0.012)$, antepartum hemorrhage $(19.2 \%$ vs $14.6 \% ; P=0.05)$, and cesarean $(27.9 \%$ vs $12.4 \% ; P<0.001)$ were significantly higher in GDM women. Neonates were at increased risk of preterm birth $(12.6 \%$ vs $8.3 \% ; P=0.03)$, macrosomia $(10.3 \%$ vs $5.9 \% ; P=0.01)$, and birth trauma $(8 \%$ vs $3 \% ; P<0.001)$.

Conclusion: The study findings revealed that GDM was higher in women in Qatar and that they were at increased risk of developing maternal and neonatal complications. Obesity emerged as an essential risk factor for subsequent GDM. The advanced maternal age, low monthly income, family history of diabetes, and obesity were the main significant risk factors for GDM.

Keywords: gestational diabetes, obstetric risks, macrosomic, Qatar

\section{Introduction}

Gestational diabetes (GDM) is a glucose tolerance disorder that occurs or is diagnosed for the first time during pregnancy. ${ }^{1}$ GDM is a public health problem that currently affects a large part of the female population and has short- and long-term consequences for the fetus and the mother. It has been reported that GDM affects $1 \%-14 \%$ of all pregnancies, and that its incidence has been steadily rising. ${ }^{2}$ GDM is a major cause 
of perinatal morbidity and mortality, as well as maternal morbidity. ${ }^{3}$ It is therefore highly important that these mothers are diagnosed during pregnancy and that they have a regular postpartum follow-up for identification and treatment of any complications.

Although the risks associated with GDM are well recognized, the impact on maternal and neonatal health outcomes is less clear. The factors that have been postulated to influence the risk of GDM among mothers include obesity, a positive family history of diabetes, treatment for infertility, recurrent urinary tract infections, macrosomic infant, unexplained neonatal death, prematurity, pre-eclampsia, diabetes in previous pregnancy, and advancing maternal age. ${ }^{4}$ Women with GDM have increased risk for potential morbidity and for impaired glucose tolerance, and it identifies a population of women who are at high risk of developing type 2 diabetes in the years following the pregnancy. ${ }^{5}$ In addition to higher risk of perinatal morbidity, the offspring of mothers with GDM face increased risk of childhood obesity and early onset of type 2 diabetes mellitus. ${ }^{6}$ GDM is a condition that can be effectively controlled, thereby decreasing the associated risks and eventually leading to the delivery of healthy infants. Thus, appropriate management of GDM will improve both maternal and perinatal outcomes.

The data on the prevalence of GDM and its complications in Asian populations are very few. ${ }^{7}$ Previous studies of Bener et $\mathrm{al}^{8-11}$ have reported that the prevalence of diabetes mellitus and its complications was high in Qatar. It was documented in the literature that GDM women and their offspring are more likely to develop metabolic syndrome or type 2 diabetes in later life. ${ }^{12,13}$ Because Qatar has a high prevalence rate of diabetes mellitus, ${ }^{8}$ it is important to determine the prevalence of GDM in women. Early diagnosis of GDM is necessary to reduce maternal and fetal morbidity and to help to prevent or delay the onset of type 2 diabetes. Therefore, this study was conducted to analyze the population characteristics of women with GDM and identify the risk factors associated with GDM.

\section{Subjects and methods}

This is a prospective cohort study that was conducted among Qatari and other Arab pregnant women over a period from January 2010 to April 2011. The study surveyed all pregnant women who attended the antenatal clinics of the Women's Hospital. The hospital is an urban hospital, and patients were referred from private clinics and primary health care centers. A representative sample of 2056 pregnant women were approached and 1608 women (78.2\%) expressed their consent to participate in the study. Women with diabetes before pregnancy were not included in the study. A total of 448 women were excluded from the study due to incomplete questionnaires or if they did not want to respond to the questionnaire due to lack of time. A series of pregnant women were taken consecutively from the register and included in the study sample. Research assistants screened medical files of the subjects for any queries about the pregnancy and neonatal complications.

In 2010 , there were a total of 16,188 deliveries in the Women's Hospital. Our study sample included 1608 pregnant women, which is $9.9 \%$ of the mothers delivered. The study was approved by both institutional review boards at the Weill Cornell Medical College and Hamad Medical Corporation prior to commencing data collection. Each participant was provided with brief information about the study and was assured of strict confidentiality.

Sociodemographic data of the pregnant women were obtained during the face-to-face interview. During the study period, women attending the antenatal clinics were screened for GDM. If any woman was found to have a risk factor for diabetes during her antenatal visits, she was screened during the same visit. If her plasma glucose on screening was $\geq 140 \mathrm{mg} / \mathrm{dL}$, she underwent a $75 \mathrm{~g}$ 2-hour oral glucose tolerance test to confirm the diagnosis of GDM. Women who did not have GDM were followed up until the third trimester of pregnancy, then every fortnight in the third trimester of pregnancy. There was a follow-up for both the groups until their delivery at the clinic for identifying maternal and neonatal complications. Body mass index (BMI) was calculated by dividing the weight in kilograms by the height in meters squared.

A well-designed and pilot-tested questionnaire was used to collect data. Face-to-face interviews were conducted by qualified nurses using a validated selfadministered questionnaire in the local language. The questionnaire covered sociodemographic characteristics of the pregnant women, family and medical history, type of maternal complication, and neonatal outcome. A translated Arabic version of the questionnaire was revised by a bilingual consultant. The survey instrument was then tested on 100 randomly selected pregnant women from the list for the validity of the questionnaire. The investigators had made the necessary corrections and modifications after considering the minor differences and discrepancies that had been found during the pilot study.

Statistical analyses were performed using SPSS software (v 18.0; SPSS Inc, Chicago, IL). Fisher's exact test 
and $\chi^{2}$ analysis were performed to test for differences in the proportions of categorical variables between two or more groups. Student's $t$-test (two-tailed) was used to determine the significance of difference between two continuous variables and confirmed by nonparametric Mann-Whitney test. Multiple logistic regression analysis using the forward inclusion and backward deletion method was used to assess the relationship between dependent and independent variables and to adjust for potential confounders and orders of importance of risk factors (determinant) for the GDM. The level $P<0.05$ was taken as the cut-off value for significance.

\section{Results}

Table 1 shows the prevalence and sociodemographic characteristics of pregnant women with GDM and without GDM. The prevalence of GDM was $16.3 \%$, with $8.8 \%$ among Qatari women and $7.5 \%$ among other Arab women. Women who had

Table I Sociodemographic risk factors for gestational diabetes mellitus (GDM) in Qatar ( $N=1608)$

\begin{tabular}{|c|c|c|c|}
\hline Variables & $\begin{array}{l}\text { GDM } \\
(n=262)\end{array}$ & $\begin{array}{l}\text { Non-GDM } \\
(n=1346)\end{array}$ & $P$ value* \\
\hline Mean age (years) & $33.4(6.5)$ & $31.9(6.3)$ & 0.001 \\
\hline \multicolumn{4}{|l|}{ Nationality } \\
\hline Qatari & $142(54.2)$ & $604(44.9)$ & \multirow[t]{2}{*}{0.008} \\
\hline Non-Qatari & $120(45.8)$ & $742(55.1)$ & \\
\hline \multicolumn{4}{|l|}{ Age group (years) } \\
\hline$<25$ & $35(13.4)$ & $224(16.6)$ & \\
\hline $25-34$ & $109(4 \mid .6)$ & $679(50.4)$ & \multirow[t]{2}{*}{0.001} \\
\hline $35-45$ & $118(45)$ & $443(32.9)$ & \\
\hline \multicolumn{4}{|l|}{ Education level } \\
\hline Illiterate & $14(5.3)$ & $89(6.6)$ & \multirow[t]{5}{*}{0.167} \\
\hline Primary & $33(12.6)$ & II 8 (8.8) & \\
\hline Intermediate & $26(9.9)$ & $126(9.4)$ & \\
\hline Secondary & $73(27.9)$ & $45 \mathrm{I}(33.5)$ & \\
\hline University & $116(44.3)$ & $562(4 \mid .8)$ & \\
\hline \multicolumn{4}{|l|}{ Occupation } \\
\hline Housewife & $165(63)$ & $810(60.2)$ & \multirow[t]{5}{*}{0.519} \\
\hline Sedentary/professional & $64(24.4)$ & $379(28.2)$ & \\
\hline Manual & $22(8.4)$ & $89(6.6)$ & \\
\hline Business & $8(3.1)$ & $4 \mid(3.0)$ & \\
\hline Police/army & $3(1.1)$ & $27(2.0)$ & \\
\hline \multicolumn{4}{|l|}{ Housing condition } \\
\hline Villa & $193(73.3)$ & $860(63.9)$ & \multirow[t]{3}{*}{0.005} \\
\hline Traditional house & $48(18.3)$ & $377(28)$ & \\
\hline Apartment & $21(8.0)$ & $109(8.1)$ & \\
\hline \multicolumn{4}{|c|}{ Monthly income (Qatari Riyal) } \\
\hline$<5000$ & $17(6.5)$ & $124(9.2)$ & \\
\hline 5000-9999 & $117(44.7)$ & $497(36.9)$ & \multirow[t]{4}{*}{0.075} \\
\hline $10,000-14,999$ & $57(21.8)$ & $278(20.7)$ & \\
\hline $15,000-20,000$ & 51 (19.5) & $298(22.1)$ & \\
\hline$>20,000$ & $20(7.6)$ & 149 (II.I) & \\
\hline
\end{tabular}

Note: *Based on $\chi^{2}$ test.
GDM were significantly older ( $33.4 \pm 6.5$ years) than women who had no $\operatorname{GDM}(31.9 \pm 6.3$ years $)(P=0.001)$. Women with GDM were more likely to be in the age group 35-45 years (45\%; $P=0.001)$. There was no significant difference in the level of education and occupation between the two groups, but most of the GDM women were more likely to be of a lower economic status (Qatari Riyal 5000-9999 [44.7\%]).

Table 2 reveals the determinants of GDM according to family and medical history. A total of $31.7 \%$ of women with GDM had a positive family history of diabetes, compared with $12.8 \%$ in normal women $(P<0.001)$. Consanguinity was higher in women with GDM (52.7\%) than in normal women $(48.9 \%)$. Women who had GDM were significantly more parous ( $>$ four children $55.3 \% ; P=0.004$ ) and obese (59.2\%; $P<0.001)$. Past history of abortion ( $24 \%$ vs $16.9 \%$; $P=0.006)$ and stillbirth $(11.8 \%$ vs $7.9 \% ; P=0.04)$ were significant past obstetric risks in GDM women compared with the normal group.

Table 3 compares the maternal and neonatal complications between women with GDM and normal women. Women with GDM were more likely to develop pregnancy-induced hypertension ( $19.1 \%$ vs $10.3 \% ; P<0.001)$, pre-eclampsia (7.3\% vs $3.8 \% ; P=0.012)$, antepartum hemorrhage (19.2\% vs $14.6 \%$; $P=0.05)$, preterm labor $(19.8 \%$ vs $8.5 \% ; P<0.001)$, and cesarean delivery $(27.9 \%$ vs $12.4 \%$; $P<0.001)$ than those without GDM. Infants born to women with GDM were at increased risk of being born preterm $(12.6 \%$ vs $8.3 \% ; P=0.03)$ and were also significantly more likely to be macrosomic $(10.3 \%$ vs $5.9 \% ; P=0.012)$. Birth trauma was significantly higher in offspring of GDM mothers ( $8 \%$ vs $3 \% ; P<0.001)$.

Table 2 Determinants of gestational diabetes mellitus (GDM) according to family and medical history $(N=1608)$

\begin{tabular}{|c|c|c|c|}
\hline Predictors & $\begin{array}{l}\text { GDM } \\
(n=262)\end{array}$ & $\begin{array}{l}\text { Non-GDM } \\
(n=1346)\end{array}$ & $P$ value* \\
\hline Consanguinity & $138(52.7)$ & $658(48.9)$ & 0.262 \\
\hline Family history of diabetes & $83(31.7)$ & $172(12.8)$ & $<0.001$ \\
\hline \multicolumn{4}{|l|}{ Parity number } \\
\hline$<2$ & $53(20.2)$ & $379(28.2)$ & \\
\hline $2-3$ & $64(24.4)$ & $364(27)$ & 0.004 \\
\hline$>4$ & $145(55.3)$ & $603(44.8)$ & \\
\hline Appropriate antenatal care & $206(78.6)$ & $1042(77.4)$ & 0.667 \\
\hline \multicolumn{4}{|l|}{ Body mass index } \\
\hline$<25$ & $35(13.4)$ & $478(35.5)$ & $<0.001$ \\
\hline $25-30$ & $72(27.5)$ & $529(39.3)$ & \\
\hline$>30$ & $155(59.2)$ & $339(25.2)$ & \\
\hline \multicolumn{4}{|l|}{ Obstetric risks in the past } \\
\hline Abortion & $63(24)$ & $228(16.9)$ & 0.006 \\
\hline Stillbirth & $31(11.8)$ & 107 (7.9) & 0.040 \\
\hline
\end{tabular}

Note: *Based on $\chi^{2}$ test. 
Table 3 Comparison of maternal and neonatal complications between women with gestational diabetes mellitus (GDM) and women without GDM (non-GDM)

\begin{tabular}{|c|c|c|c|}
\hline Variables & $\begin{array}{l}\text { GDM } \\
(n=262)\end{array}$ & $\begin{array}{l}\text { Non-GDM } \\
(n=1346)\end{array}$ & $P$ value* \\
\hline \multicolumn{4}{|l|}{ Maternal complications } \\
\hline $\begin{array}{l}\text { Pregnancy-induced } \\
\text { hypertension }\end{array}$ & $50(19.1)$ & $138(10.3)$ & $<0.001$ \\
\hline Pre-eclampsia & $19(7.3)$ & $51(3.8)$ & 0.012 \\
\hline Urinary tract infections & $64(24.4)$ & $353(26.2)$ & 0.543 \\
\hline Antepartum hemorrhage & $50(19.2)$ & $196(14.6)$ & 0.050 \\
\hline Preterm labor & $52(19.8)$ & $114(8.5)$ & $<0.001$ \\
\hline $\begin{array}{l}\text { Premature rupture of } \\
\text { membrane }\end{array}$ & $40(15.3)$ & $53(3.9)$ & $<0.001$ \\
\hline \multicolumn{4}{|l|}{ Labor } \\
\hline Spontaneous & $195(74.4)$ & $943(70.1)$ & 0.050 \\
\hline Induced & $40(15.3)$ & $187(13.9)$ & \\
\hline Augmented & $27(10.3)$ & $216(16.0)$ & \\
\hline \multicolumn{4}{|l|}{ Cesarean } \\
\hline Elective & $50(19.1)$ & $127(9.4)$ & $<0.001$ \\
\hline Emergency & $23(8.8)$ & $41(3.0)$ & $<0.001$ \\
\hline \multicolumn{4}{|c|}{ Neonatal complications } \\
\hline \multicolumn{4}{|l|}{ Births } \\
\hline Preterm birth & $33(12.6)$ & $112(8.3)$ & 0.03 \\
\hline Full-term birth & $229(87.4)$ & 1234 (91.7) & \\
\hline \multicolumn{4}{|l|}{ Apgar score at I minute } \\
\hline$<7$ & $56(21.4)$ & $342(25.4)$ & 0.166 \\
\hline$\geq 7$ & $206(78.6)$ & $1004(74.6)$ & \\
\hline \multicolumn{4}{|l|}{ Apgar score at 5 minutes } \\
\hline$<7$ & $22(8.4)$ & $|3|(9.7)$ & 0.500 \\
\hline$\geq 7$ & $240(91.6)$ & $1215(90.3)$ & \\
\hline \multicolumn{4}{|l|}{ Birth weight (g) } \\
\hline $\begin{array}{l}\text { Low birth weight } \\
(<2500)\end{array}$ & $12(4.6)$ & $99(7.4)$ & 0.012 \\
\hline $\begin{array}{l}\text { Normal weight } \\
(2500-4000)\end{array}$ & $223(85.1)$ & II 67 (86.7) & \\
\hline Macrosomia $(>4000)$ & $27(10.3)$ & $80(5.9)$ & \\
\hline \multicolumn{4}{|l|}{ Birth defects } \\
\hline Birth trauma & $21(8.0)$ & $4 I(3.0)$ & $<0.001$ \\
\hline Jaundice & $33(12.6)$ & $83(6.2)$ & $<0.001$ \\
\hline Congenital anomaly & $9(3.4)$ & $38(2.8)$ & 0.591 \\
\hline Growth retardation & $14(5.3)$ & $4 I(3.0)$ & 0.060 \\
\hline Sepsis antibiotics & $21(8.0)$ & $49(3.6)$ & 0.001 \\
\hline
\end{tabular}

Note: *Based on $\chi^{2}$ test.

Table 4 shows the predictors for GDM in women and their offspring using stepwise logistic regression analysis. Low monthly income (odds ratio [OR]: 1.9, 95\% confidence intervals $[\mathrm{CI}]: 1.1-3.2 ; P=0.05)$, advanced maternal age (35-45 years) (OR: $1.7,95 \%$ CI: $1.2-2.6 ; P=0.001)$, obesity (OR: 6.6, 95\% CI: 4.4-9.9; $P<0.001$ ), family history of diabetes (OR: 3.6, 95\% CI: 2.5-5.0; $P<0.001$ ), previous history of abortion (OR: $1.4,95 \% \mathrm{CI}: 1.1-2.0 ; P=0.048$ ), macrosomia (OR: 1.4, 95\% CI: 1.1-2.3; $P=0.046$ ), antepartum hemorrhage (OR: 2.2, 95\% CI: $1.4-3.6 ; P=0.001$ ), and emergency cesarean (OR: 2.7, 95\% CI: 1.9-3.7; $P<0.001$ ) were the main factors associated with GDM.
Table 4 Stepwise logistic regression analysis for gestational diabetes mellitus (GDM) $(N=1608)$

\begin{tabular}{|c|c|c|c|}
\hline Predictors & OR & $95 \% \mathrm{Cl}$ & $P$ value* \\
\hline Low monthly income & 1.9 & $1.1-3.2$ & 0.050 \\
\hline \multicolumn{4}{|l|}{ (Qatari Riyal) } \\
\hline \multicolumn{4}{|l|}{ Age group (years) } \\
\hline$<25$ (ref) & I & & 0.001 \\
\hline $25-34$ & I.I & $0.7-1.5$ & \\
\hline $35-45$ & 1.7 & $1.2-2.6$ & \\
\hline \multicolumn{4}{|l|}{ Body mass index } \\
\hline$<25$ (ref) & $\mathrm{I}$ & & $<0.001$ \\
\hline $25-30$ & 1.7 & $1.1-2.7$ & \\
\hline$>30$ & 6.6 & $4.4-9.9$ & \\
\hline Family history of diabetes & 3.6 & $2.5-5.0$ & $<0.001$ \\
\hline Previous abortion & 1.4 & $1.1-2.0$ & 0.048 \\
\hline \multicolumn{4}{|l|}{ Neonatal birth weight (g) } \\
\hline $2500-4000$ (ref) & I & & 0.046 \\
\hline$<2500$ & 0.5 & $0.3-0.9$ & \\
\hline$>4000$ & I.4 & $1.1-2.3$ & \\
\hline Antipartum hemorrhage & 2.2 & $1.4-3.6$ & 0.001 \\
\hline \multicolumn{4}{|l|}{ Cesarean } \\
\hline Elective $(\mathrm{y} / \mathrm{n})$ & 2.3 & $1.6-3.2$ & $<0.001$ \\
\hline Emergency $(y / n)$ & 2.7 & $1.9-3.7$ & $<0.001$ \\
\hline
\end{tabular}

Note: $*$ Two-sided $P$ value based on -2 log likelihood statistics. Abbreviations: $\mathrm{Cl}$, confidence interval; $\mathrm{OR}$, odds ratio; ref, reference category.

Table 5 presents the global prevalence rate of gestational diabetes mellitus across different countries. Figure $1 \mathrm{com}-$ pares the main associated factors of GDM between women with GDM and normal women.

\section{Discussion}

To the best of our knowledge, this study is the first attempt to examine the prevalence of GDM and its associated factors among women in Qatar. GDM is one of the most common medical complications in pregnancy, and there is a general consensus that the incidence of GDM is increasing globally. Through this prospective cohort study we have examined the prevalence of GDM and its associated factors in mothers and their offspring. The prevalence of GDM in our study sample was $16.3 \%$, which is higher than the rates observed in the neighboring Gulf countries Bahrain ${ }^{14}$ and Saudi Arabia (12.5\%), ${ }^{15}$ but lower than the rate of the United Arab Emirates (20.6\%). ${ }^{16}$ These rates are comparable to the incidence rate reported in the literature that the incidence of GDM ranges $1 \%-14 \%$ of all pregnancies. ${ }^{17} \mathrm{Also}$, the prevalence rate in Qatar found a similar rate in developed countries like Canada $(17.8 \%)^{18}$ and France $(12.1 \%),{ }^{19}$ but was higher than the rate observed in Australia $(9.5 \%)^{20}$ and the US (4.8\%). ${ }^{5}$ However, the study revealed that GDM was considerably higher among women in Qatar.

This study provides information about the risks of GDM, which could potentially help to incorporate early intervention measures. Our studied women with GDM had a higher risk 


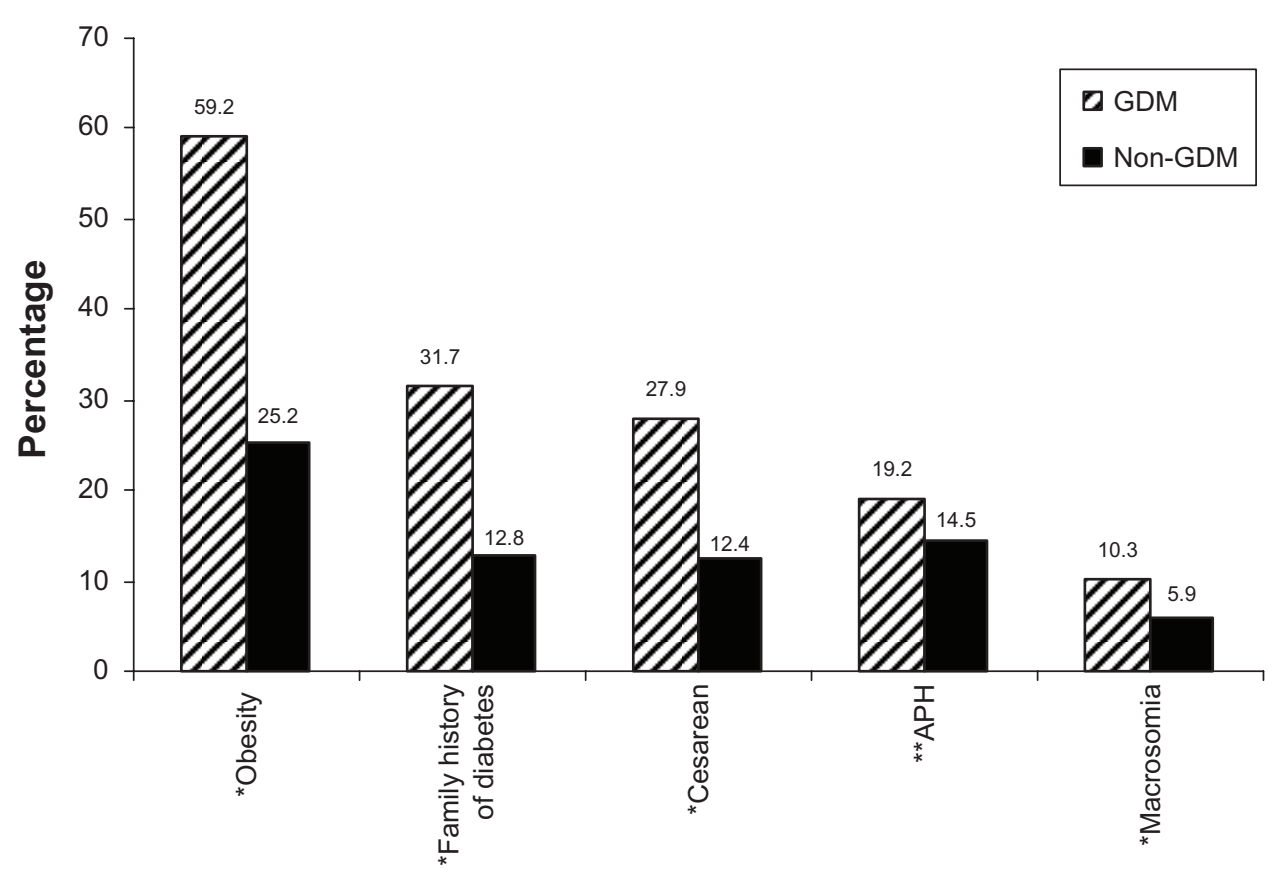

Risk factors

Figure I Comparison of the associated factors of gestational diabetes mellitus (GDM) between women with GDM and normal women (non-GDM). Notes: $* P<0.001 ; * * P=0.058$.

Abbreviation: $\mathrm{APH}$, antepartum hemorrhage.

of adverse health outcomes and were more likely to develop maternal complications. The most common risk factors observed in the studied women with GDM were advanced maternal age, low economic status, increasing maternal BMI, family history of diabetes, and parity. The potential outcomes associated with GDM were maternal complications like pregnancy-induced hypertension, pre-eclampsia, antepartum hemorrhage, cesarean, and neonatal complications like macrosomia, preterm birth, birth trauma, and congenital anomalies. A study conducted in Iran has also confirmed that there is a higher risk of pregnancy complications and adverse fetal outcomes with GDM. ${ }^{21}$

It was reported that socioeconomic status influences the prevalence of DM in pregnancy. ${ }^{22}$ On the contrary, there was

Table 5 Global prevalence rate (\%) of gestational diabetes mellitus across different countries

\begin{tabular}{|c|c|c|c|c|c|}
\hline Country & Reference & Year & $\begin{array}{l}\text { Sample } \\
\text { size }\end{array}$ & Diagnostic criteria & $\begin{array}{l}\text { Prevalence } \\
\text { rate (\%) }\end{array}$ \\
\hline Saudi Arabia & Ardawi et al ${ }^{15}$ & 2000 & 1056 & $\begin{array}{l}\text { I hour } 50 \mathrm{~g} \mathrm{GCT} \text {, cut-off } 130 \mathrm{mg} / \mathrm{dL} \text {, followed by } 3 \text { hours } \\
\text { fasting } 100 \mathrm{~g} \text { OGTT after } 3 \text { days of } 200 \mathrm{~g} \mathrm{CHO} \text { per day }\end{array}$ & 12.5 \\
\hline Bahrain & Al Mahroos et al ${ }^{14}$ & $200 I-2002$ & 10,495 & $\begin{array}{l}\text { I hour } 50 \mathrm{~g} \text { GCT, cut-off } 140 \mathrm{mg} / \mathrm{dL} \text { followed by } 3 \text { hours } \\
\text { fasting } 75 \mathrm{~g} \text { OGTT }\end{array}$ & 13.5 \\
\hline Malaysia & Tan et $\mathrm{al}^{31}$ & 2006 & 1600 & $\begin{array}{l}\text { I hour } 50 \mathrm{~g} \text { GCT, cut-off } 140 \mathrm{mg} / \mathrm{dL} \text { followed by } 3 \text { hours } \\
\text { fasting } 75 \mathrm{~g} \text { OGTT }\end{array}$ & $1 \mathrm{I} .4$ \\
\hline $\begin{array}{l}\text { United Arab } \\
\text { Emirates }\end{array}$ & Agarwal et al ${ }^{16}$ & 2007 & 1172 & 2 hours fasting $75 \mathrm{~g}$ OGTT, cut-off $\geq 140 \mathrm{mg} / \mathrm{dL}$ & 20.6 \\
\hline India & Seshiah et $\mathrm{al}^{30}$ & 2008 & $4|5|$ & 2 hours fasting $75 \mathrm{~g}$ OGTT, cut-off $\geq 140 \mathrm{mg} / \mathrm{dL}$ & 17.8 \\
\hline US & Ferrara $^{5}$ & 1996 & 28,330 & $\begin{array}{l}\text { I hour } 50 \mathrm{~g} \text { GCT, cut-off } 140 \mathrm{mg} / \mathrm{dL} \text {, followed by } 3 \text { hours } \\
\text { fasting } 100 \mathrm{~g} \text { OGTT }\end{array}$ & 4.8 \\
\hline Australia & Moses et $\mathrm{al}^{20}$ & 2010 & 1275 & $\begin{array}{l}\text { I hour } 50 \mathrm{~g} \mathrm{GCT}, 2 \text { hours } 75 \mathrm{~g} \text { OGTT after overnight fast, } \\
\text { cut-off I } 40 \mathrm{mg} / \mathrm{dL} \text { (ADIPS) criteria }\end{array}$ & 9.5 \\
\hline Canada & Ryan 18 & 2010 & 4150 & Random plasma glucose screening and 2 hours 75 g OGTT & 17.8 \\
\hline France & Schneider et a $\left.\right|^{19}$ & 2006 & 11,545 & 2 hours fasting $75 \mathrm{~g}$ OGTT, cut-off $\geq 140 \mathrm{mg} / \mathrm{dL}$ & 12.1 \\
\hline Qatar & Present study & $2010-2011$ & 1608 & 2 hours fasting $75 \mathrm{~g}$ OGTT, cut-off $\geq 140 \mathrm{mg} / \mathrm{dL}$ & $\begin{array}{l}16.3 \\
\text { Qatari: } 8.8 \\
\text { Other Arab: } 7.5\end{array}$ \\
\hline
\end{tabular}

Abbreviations: ADIPs, Australasian Diabetes in Pregnancy Society; CHO, carbohydrate; GCT, glucose challenge test; OGTT, oral glucose tolerance test. 
no significant difference in level of education and job status between both the groups except for their advanced maternal age and low monthly income in the study sample. The proportion of GDM increased with increasing age: $13.4 \%$ in women below 25 years, $41.6 \%$ in women aged $25-34$ years, and $45 \%$ in women aged $35-45$ years. Although we did not find any significant difference between both the groups in their socioeconomic status, women with GDM were often of lower economic status (44.7\%) and housewives (63\%). This shows that women with GDM may have had a poor understanding of diabetes and its significance. To improve outcomes in women with GDM, vigorous attempts need to be made to raise their educational awareness.

In terms of family and medical history of women with GDM, the data revealed that GDM was more prevalent in women with a family history of diabetes (31.7\%), those who were more parous $(55.3 \%)$, and those who were obese $(59.2 \%)$ compared with the normal group. Our study showed that overweight and obese women were more prone to developing GDM, as observed in other studies. ${ }^{23,24}$ Hence, obese women considering pregnancy should be informed of all the risks of maternal obesity and of how it can complicate their pregnancies. Epidemiologic studies have consistently identified a family history of diabetes and increased parity as primary risk factors for the development of GDM..$^{25-27}$

In the study sample, the risk of adverse maternal outcome overall was higher in women with GDM compared with normal women. Women with GDM were at increased risk of developing pregnancy-induced hypertension (19.1\%), pre-eclampsia $(7.3 \%)$, antepartum hemorrhage $(19.2 \%)$, preterm labor $(19.8 \%)$, premature rupture of membrane (15.3\%), and have cesarean section (27.9\%) than those with a normal glucose tolerance. Similar results have been reported in previous studies ${ }^{28,29}$ that pregnancy-induced hypertension (17.9\%) and cesarean session (17.1\%) were higher in women with GDM than in those with normal glucose. Another study also indicated similar maternal complications among GDM women in China. ${ }^{7}$

For the neonates, the study findings revealed that they are at increased risk of macrosomia, birth injuries, and hyperbilirubinemia, which is similar to the results found in a study by Langer et al. ${ }^{4}$ The study identified an increased risk of macrosomia (10.3\%), preterm birth (12.6\%), jaundice $(12.6 \%)$, and birth trauma (8\%) among offspring of GDM mothers. This may be explained by the higher rate of pregnancy-induced hypertension and cesarean delivery for fetal distress among GDM mothers. Another study by Hong et $\mathrm{al}^{28}$ reported that infants born to GDM mothers were more likely to be born preterm $(10.7 \%$ vs $6.4 \%)$ or have macrosomia (4.3\% vs 1.7\%). Prevention of macrosomia and perinatal complications are primary goals in the treatment of women with pregnancies complicated by GDM.

It is evident from the aforementioned study findings that the presence of maternal diabetes mellitus during pregnancy has important consequences for both mother and child. Stepwise logistic regression revealed that advanced maternal age, obesity, family history of diabetes, antepartum hemorrhage, cesarean section, and macrosomia were significant associated risk factors for GDM among women in Qatar. The greatest perinatal risk in GDM cases is fetal macrosomia, which has been associated with a higher rate of cesarean delivery. As seen in the results, GDM is seen more frequently in obese women and can be an important confounder for the association with birth weight.

Out of the six risk factors observed in the current study, obesity is a modifiable factor clearly associated with GDM. Hence, there is a need for more research on the effectiveness of various interventions aimed at reducing weight among women of reproductive age and their impact on pregnancy complications. This study demonstrated that the risk of these outcomes can be reduced by obstetricians with standard treatment consisting of individual dietary and lifestyle advice during pregnancy.

\section{Conclusion}

The present study revealed that GDM was higher in women in Qatar and that they were at increased risk of developing pregnancy-induced hypertension, pre-eclampsia, antepartum hemorrhage, premature rupture of membrane, and cesarean delivery. The risk of GDM increased steadily with maternal BMI, and obesity emerged as an essential risk factor for subsequent GDM. Infants born to women with GDM were significantly more likely to be macrosomic. Congenital anomalies and birth injuries were significantly higher in the offspring of GDM mothers. Advanced maternal age, low monthly income, family history of diabetes, and obesity were the main associated risk factors for GDM.

\section{Acknowledgments}

The project was supported partly by Qatar Diabetes Association, Qatar Foundation, and Qatar National Research Fund Grant No. UREP-08-090-3-018. We would also like to thank Hamad Medical Corporation (HMC Research Protocol \#10146/10) and the Weill Cornell Medical College-Qatar Institutional Review Board (IRB\# 2010-0021) for their ethical approval of this study. 


\section{Disclosure}

The authors report no conflicts of interest in this work.

\section{References}

1. Kaaja RJ, Greer IA. Manifestations of chronic disease during pregnancy. JAMA. 2005;294:2751-2757.

2. American Diabetes Association. Diagnosis and classification of diabetes mellitus. Diabetes Care. 2007;30:S45-S46.

3. Gabbe SG, Graves CR. Management of diabetes mellitus complicating pregnancy. Obstet Gynecol. 2003;102:857-868.

4. Langer O, Yogev Y, Most O, Xenakis EM. Gestational diabetes: the consequences of not treating. Am J Obstet Gynecol. 2005;192:989-997.

5. Ferrara A. Increasing prevalence of gestational diabetes mellitus. Diabetes Care. 2007;30:S141-S146.

6. Silverman BL, Rizzo TA, Cho NH, Metzger BE. Long term effects of the intrauterine environment. Northwestern University Diabetes in Pregnancy Center. Diabetes Care. 1998;21:B142-B149.

7. Yang X, Hsu-Hage B, Zhang H, et al. Gestational diabetes mellitus in women of single gravidity in Tianjin City, China. Diabetes Care. 2002; 25:847-851.

8. Bener A, Zirie M, Janahi IM, Al-Hamaq AO, Musallam M, Wareham NJ. Prevalence of diagnosed and undiagnosed diabetes mellitus and its risk factors in a population-based study of Qatar. Diabetes Res Clin Pract. 2009;84:99-106.

9. Bener A, Zirie M, Al-Rikabi R. Genetics, obesity and environmental risk factors associated with type 2 diabetes. Croat Med J. 2005;46: 302-307.

10. Bener A, Micallef R, Afifi M, Derbala M, Al-Mulla HM, Usmani MA Association between type 2 diabetes mellitus and helicobacter pylori infection. Turk J Gastroenterol. 2007;18(4);225-229.

11. Bener A, Al-Saied A, Al-Ali MG, et al. Vitamin D deficiency in the young population with type 1 diabetes: a case-control study. Diabetes Res Clin Pract. 2008;79:S37-S37.

12. Boney CM, Verma A, Tucker R, Vohr BR. Metabolic syndrome in childhood: association with birth weight, maternal obesity, and gestational diabetes mellitus. Pediatrics. 2005;115:e290-e296.

13. Lee H, Jang HC, Park HK, Metzger BE, Cho NH. Prevalence of type 2 diabetes among women with a previous history of gestational diabetes mellitus. Diabetes Res Clin Pract. 2008;81:124-129.

14. Al Mahroos S, Nagalla DS, Yousif W, Sanad H. A population based screening for gestational diabetes mellitus in non-diabetic women in Bahrain. Ann Saudi Med. 2005;25:129-133.

15. Ardawi MSM, Nasrat HA, Jamal HS, Al-Sagaaf HM, Mustafa BE Screening for gestational diabetes mellitus in pregnant females. Saudi Med J. 2000;21:155-160.
16. Agarwal MM, Dhatt GS, Zayed R, Bali N. Gestational diabetes: relevance of diagnostic criteria and preventive strategies for type 2 diabetes mellitus. Arch Gynecol Obstet. 2007;276:237-243.

17. Bevier WC, Jovanovic-Peterson L, Peterson CM. Diagnosis, management and outcome of gestational diabetes. Endocrinol Metab Clin North Am. 1995;24:103-138.

18. Ryan EA. Diagnosing gestational diabetes. Diabetologia. 2011;54: 480-486.

19. Schneider S, Hoeft B, Freerksen N, et al. Neonatal complications and risk factors among women with gestational diabetes mellitus. Acta Obstetricia et Gynecologica Scandinavia. 2010;90:231-237.

20. Moses RG, Morris GJ, Petocz P, San Gil F, Garg D. The impact of potential new diagnostic criteria on the prevalence of gestational diabetes mellitus in Australia. Med J Aust. 2011;194:338-340.

21. Keshavarz M, Cheung NW, Babaee GR, Moghadam HK, Ajami ME, Shariati M. Gestational diabetes in Iran: incidence, risk factors, and pregnancy outcome. Diabetes Res Clin Pract. 2005;69:279-286.

22. El-Hazmi MAF, Warsy AS, Al-Swailem AR, Al-Swailem AM, Sulaimani R. Diabetes mellitus as a health problem in Saudi Arabia. East Mediterr Health J. 1998;4:58-66.

23. Doherty DA, Mogann EF, Francis J, Morrison JC, Newnham JP. Pre-pregnancy body mass index and pregnancy outcomes. Int $J$ Gynaecol Obstet. 2006;95:242-247.

24. Hadaegh F, Tohidi M, Harati H, Kheirandish M, Rahimi S. Prevalence of GDM in southern Iran (Bandar Abbas City). Endocr Pract. 2005;11: 313-318.

25. Ben-Haroush A, Yogev Y, Hod M. Epidemiology of GDM and its association with type 2 diabetes. Diabet Med. 2004;21:103-113.

26. Teh WT, Teede HJ, Paul E, Harrison CL, Wallace EM, Allan C. Risk factors for gestational diabetes mellitus: implications for the application of screening guideline. Aust N Z J Obstet Gynaecol. 2011;51:26-30.

27. Chu SY, Callaghan WM, Kim SY, et al. Maternal obesity and risk of gestational diabetes mellitus. Diabetes Care. 2007;30:2070-2076.

28. Hong JU, Rumbold AR, Wilson KJ, Crowther CA. Borderline gestational diabetes mellitus and pregnancy outcomes. BMC Pregnancy Childbirth. 2008;8:31.

29. Gunderson EP, Lewis CE, Tsai AL, et al. A 20 year prospective study of childbearing and incidence of diabetes in young women, controlling for glycemia before conception; the Coronary Artery Risk Development In Young Adults (CARDIA) Study. Diabetes. 2007;56:2990-2996.

30. Seshiah V, Balaji V, Balaji MS, et al. Prevalence of gestational diabetes mellitus in south India (Tamil Nadu): a community based study. JAssoc Physicians India. 2008;56:329-333.

31. Tan PC, Ling LP, Omar SZ. Screening for gestational diabetes at antenatal booking in a Malaysian university hospital: the role of risk factors and threshold value for the $50 \mathrm{~g}$ glucose challenge test. Aust N Z J Obstet Gynaecol. 2007;47:191-197.
International Journal of Women's Health

\section{Publish your work in this journal}

The International Journal of Women's Health is an international, peerreviewed open-access journal publishing original research, reports, reviews and commentaries on all aspects of women's healthcare including gynecology, obstetrics, and breast cancer. Subject areas include: Chronic conditions (migraine headaches, arthritis, osteoporosis);

\section{Dovepress}

Endocrine and autoimmune syndromes; Sexual and reproductive health; Psychological and psychosocial conditions. The manuscript management system is completely online and includes a very quick and fair peer-review system. Visit http://www.dovepress.com/ testimonials.php to read real quotes from published authors. 